\title{
SÓCRATES, GLAUCÓN Y ADIMANTO DISCUTEN QUE CLASE DE BIEN ES LA JUSTICIA*
}

(POLITEIA, LIBRO II)

\section{Clasificación tripartita de los bienes}

Al iniciarse el coloquio, el hijo de Sofronisco cuenta cómo, concluida la disputa con Trasímaco (al término del libro I de la República), Glaucón, declarándose insatisfecho lo mismo con las opiniones del sofista que con los argumentos de Sócrates, pide a éste que antes de tomar partido en favor o en contra de la tesis es mejor ser justo que injusto, primeramente esclarezca qué clase de bien es la justicia.

¿Puede sostenerse que tal planteamiento es incongruente con la afirmación, hecha por Sócrates al final del libro I de la Politeia, de que mientras no se sabe qué es lo justo, malamente podrá decirse "si resulta ser o no una virtud, y si quien la tiene es o no es feliz?" 1

R. G. Cross y A. D. Woozley piensan que el cargo de incongruencia difícilmente es defendible en el caso, ya que lo único que Sócrates hace al responder a la pregunta de Glaucón es exponer un punto de vista cuya corrección demostrará más tarde. Nada objetable hay, según aquellos autores, en que, al iniciarse un diálogo, un filósofo anuncie a qué conclusión habrá de llegar, con tal de que después presente los argumentos que conducen a tal resultado. "Como cuestión de procedimiento, a veces es más claro hacer del orden expositivo el reverso del orden de la prueba", práctica a la que nos ha acostumbrado "el aprendizaje de la geometría euclidiana", pues en ésta se enuncia en primer término el teorema que ha de probarse, y la prueba se ofrece en seguida hasta concluir con la fórmula quod erat demonstrandum". ${ }^{2}$ Por otra parte, hay que tener presente que quien hace la mencionada pregunta no es Sócrates, sino Glaucón. El filósofo se limita a dar una respuesta, tan categórica como breve. Antes de referirnos a ella, escuchemos lo que Glaucón dice. En su concepto, hay tres clases de bienes:

Pertenecen a la primera "los que escogeriamos tener no por los efectos que producen, sino por sí mismos, como, por ejemplo, regocijarse, o esos pla-

- Capitulo del libro Teorias sobre la justicia en los diálogos de Platón, en prensa.

I República, libro I, $354 c$.

2 R. C. Cross y A. D. Woozley, Plato's Republic. A Philosophical Commentary. Macmillan, St. Martin's Press, reimpresión del año 1970, p. 62. 
ceres innocuos de los que pasado el tiempo nada resulta, salvo la alegría de haberlos experimentado" $(357 b)^{3}$

Forman la segunda los que amamos a la vez por sí mismos y por sus consecuencias, como pensar, ver y gozar de salud ( $357 c$ ).

Existe, por último, "una tercera especie en la que incluimos hacer ejercicio; ser curados cuando estamos enfermos; el arte de curar y el de hacer dinero". De ellos aseveramos que "son penosos pero últiles para nosotros, y que no los escogeríamos por si mismos", sino en vista de las ventajas que de ellos se siguen ( $357 \mathrm{c}$ ).

Cuando Glaucón demanda a Sócrates en cuál de tales categorías incluye a la justicia, el segundo responde: en la más hermosa, "la que el hombre que pretende ser bienaventurado debe amar tanto por sí misma cuanto por sus efectos".

Glaucón estima en cambio que para la mayoría de los hombres la justicia forma parte de "esa difícil especie de actividades" que son practicadas "en vista de las consecuencias y del buen nombre que la opinión engendra, pero que en sí mismas han de evitarse por lo que de penoso tienen" (358 a).

Tal es -observa Sócrates_ no sólo el parecer de los más, sino también el de Trasímaco, quien no hace mucho ha censurado a la justicia como tal y alabado a su contraria. 4

Yo, por mi parte —Glaucón insiste- considero que el calcedonio, "cual serpiente encantada por ti, se rindió demasiado pronto", y que aún no se ha ofrecido una prueba satisfactoria de ninguna de las dos tesis antagónicas so. bre la justicia y la injusticia. Lo que anhelo "es escuchar qué cosa es y qué fuerza tiene en sí misma cada una cuando se halla en el alma, pero dejando a un lado sus recompensas y resultados. Por tanto, procederé de esta manera, si te parece bien: retomaré el argumento de Trasímaco y expondré primero qué cosa dicen los hombres que es la justicia y cómo se ha originado; en segundo lugar, cómo los que la practican lo hacen a pesar suyo, por considerarla como algo necesario, no como algo bueno"; y, por último, "que con

3 De acuerdo con estos ejemplos resulta que para Glaucón el regocijo o la alegría valen por si mismos, sea cual fuere la causa que los produce. Mas: ¿podría decirse correctamente, por ejemplo, que alegrarse del mal ajeno es un bien para el que se alegra?

4 Algunos autores - A. Menzel, por ejemplo- han sostenido que al definir la justicia Trasímaco "se limita a describir la realidad, sin proponer ideal alguno". (Menzel, Calicles, p. 64 de la traducción castellana de Mario de la Cueva, Centro de Estudios Filosóficos de la Universidad Nacional Autónoma de México, Cuaderno 15, 1964). Cuando el sofista de Calcedonia afirma que su definición de lo justo tiene un sentido político y que al hablar de los más fuertes piensa en las ciudades o, mejor dicho, en quienes las gobiernan, su tesis, según la cual "justicia es lo que conviene al más pođeroso", parece puramente descriptiva; pero cuando se pregunta si la justicia es o no más provechosa que la injusticia, y responde que al hombre indudablemente le conviene más, en lo personal, ser injusto que justo, la cuestión por él planteada es de indole estimativa, y la forma en que pretende resolverla encierra un juicio de valor. Cf. E. García Máynez, Teorias sobre la justicia en los diálogos de Platón, capítulo relativo al libro I de la Politica, sección 6. 
razón actúan de tal modo", porque "la vida del injusto es mejor que la del justo, aun cuando a mí, Sócrates, no me lo parezca" ( 358 b). "Al percibir las voces de Trasímaco y de mil más, me siento aturdido y me duelen los oídos, pues aún no he escuchado de nadie, en la forma que me gustaría, el argumento de que la justicia es mejor que la injusticia. Por esto es que, haciendo un esfuerzo, intentaré una alabanza de la vida injusta, después de lo cual te mostraré de qué manera deseo a mi vez escuchar de ti el vituperio de la injusticia y la loa de la justicia" (358 b-c).

La forma en que Glaucón presenta sus dudas no es consistente, pues en un principio declara que desea saber qué cosa es y qué fuerza tiene en si mis. ma la justicia "cuando se halla en el alma", pero dejando a un lado "sus recompensas y resultados", y más tarde afirma que los que la practican "lo hacen a pesar suyo, por considerarla como algo necesario, no como algo bueno", y que "con razón actúan de tal modo", porque "la vida del injusto es mejor que la del justo", al menos si tomamos en cuenta (cual se infiere de lo que el interlocutor de Sócrates expone más tarde) los efectos que la $\delta$ ¿xaıớvi y su contraria tienen para los que proceden justa o injustamente.

Las cuestiones que, en conexión con el tema, Glaucón considera fundamentales, son dos: $1^{a}$ ) determinar si la justicia posee o no, independientemente de las consecuencias que su ejercicio produce (para bien o mal de quien la practica) valor objetivo o intrínseco; $2^{a}$ ) esclarecer si, independientemente de que aquélla valga o no en sí y por sí, las consecuencias que engendra (para bien o daño del actuante) permiten o no sostener - atendiendo precisamente a tales consecuencias- que la vida del justo es mejor que la del inicuo.

Esta forma de exposición se explica porque, siendo la ética platónica y, en general, la griega, ética de bienes ${ }^{5}$ el problema que estriba en saber hasta qué punto las virtudes son un medio idóneo para la consecución del supremo bien llamado eudemonia, no puede soslayarse, sino que, de acuerdo con tal enfoque, es fundamental.

Según Cross y Woozley, el término consecuencias, empleado por Glaucón, debe entenderse así: "Las consecuencias de $x$ son aquellas cosas que: $a$ ) ocurren; $b$ ) ocurren después de $x$, y $c$ ) ocurren a causa de $x$ ". Los ejemplos de Platón en el libro $\mathrm{X}(612 \mathrm{~b})$, a saber, "los honores y recompensas que recibe

5 Se da el nombre de ética de bienes o de fines a las doctrinas que afirman la existencia de un bien último o supremo hacia cuyo logro deben hallarse orientados los esfuerzos del hombre. En tanto que el relativismo ético conduce a la negación de normas y criterios objetivos de moralidad, la ética de bienes refiere el mérito de nuestras acciones a la relación que las mismas guardan con el último fin de la vida, frente al cual todos los demás son sólo medios. Si los bienes se enlazan unos con otros en función de su importancia, la misión primordial del moralista habrá de consistir - según Aristóteles_ en encontrar una meta no susceptible de ser referida - como medio_ a otras más valiosas. Si tal bien existe, los actos del individuo deberán tender a su consecución, ya que es el único absoluto, en cuanto -a diferencia de los restantes - es un fin que ya no puede servir como punto de partida. 
el hombre que ha llevado una vida de justicia, quedan exactamente comprendidos dentro de la mencionada especificación de aquel término. Honores y recompensas son consecuencias de la justicia porque es una cuestión de hecho, un hecho contingente, que advienen al varón justo y son lo que éste razonablemente puede esperar que tarde o temprano recibirá por haber llevado una vida justa". 6 Pero tienen el carácter de "consecuencias accidentales", porque "la justicia seguiría siendo justicia aun cuando no fuese jamás reconocida ni recompensada". ${ }^{7}$ Por ello Platón dice (por boca de Sócrates) que es buena tanto por si misma cuanto por las consecuencias que engendra. ${ }^{8}$

Respecto de la clasificación que Glaucón propone conviene advertir, tomando en cuenta los ejemplos que éste ofrece, que no todos están referidos a lo que en la actualidad llamaríamos bienes, ${ }^{9} \mathrm{ni}$ a diferentes tipos de virtudes, sino que algunos, como el hecho de regocijarse (primer grupo), la capacidad de ver o de pensar (segunda especie), o la de hacer dinero (tercer grupo), normalmente no encierran un sentido ético.

\section{Origen de la justicia}

Suele afirmarse que, por naturaleza, cometer injusticias es bueno y sufrirlas malo", ${ }^{10}$ "pero que el mal de sufrirlas supera con mucho al bien de cometerlas". Por ello, cuando los hombres respectivamente las cometen y las sufren, a los que son incapaces de evitar la elección les parece que es útil convenir unos con otros en que no cometerán ni sufrirán actos injustos. Tal es el origen de las leyes y los convenios entre los hombres, "y la razón por la que éstos

6 Cross y Woozley, op. cit. en la nota 2, p. 66.

7 Idem.

8 La ética griega no establecía la moderna distinción entre valores y bienes. De acuerdo con aquélla podemos decir que la afirmación platónica de que la justicia vale tanto por sí misma cuanto por las consecuencias que engendra, oculta la distinción mencionada.

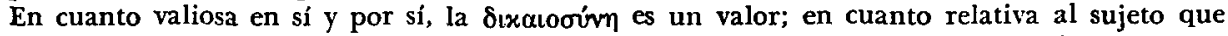
la practica y a los que por la justa actuación de aquél se benefician, asume el carácter de bien. Expresado de otro modo: la justicia no vale únicamente en sí y por sí; es, al propio tiempo, un bien para el actuante y para las personas a quienes la conducta justa se halla dirigida. Sobre el desconocimiento de los valores morales en la ética de fines, cf. $\mathbf{N}$. Hartmann, Ethik, segunda parte, cap. 27.

${ }^{9}$ Los bienes, por el hecho de serlo, son actos o, en general, cosas que valen; pero su valia es siempre relativa a las personas. En el ser de los bienes está implícito -como escribe Nicolai Hartmann_ el ser bienes para alguien. Mas la circunstancia de que algo sea un bien para un sujeto no significa que el valor del objeto dependa -según el propio Hartmann_ de los juicios estimativos de la persona para la cual la cosa vale.

$10 \mathrm{E} 1$ aserto de que, "por naturaleza", cometer injusticias es bueno, sólo puede sostenerse de acuerdo con Trasímaco y Calicles, para quienes lo justo encuentra su fundamento en la fuerza. En cuanto a la afirmación de que "sufrir injusticias es malo", debe tenerse en cuenta que el calificativo "malo" tiene en el caso el sentido de doloroso, no el de malo en la acepción ética del término. Cf. E. García Máynez, Teorias sobre la justicia en los diálogos de Platón, capítulo v, 3. 
creen que la justicia se halla a igual distancia de lo mejor, que es no ser castigado cuando se obra injustamente, y de lo peor, que consiste en no poder vengarse si se es víctima de un acto injusto" (359a-b).

De acuerdo con estas opiniones, que Glaucón atribuye a la mayoria, la

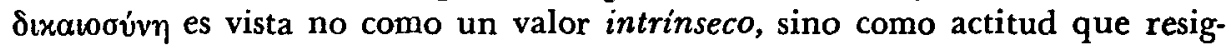
nadamente se adopta cuando no se tiene la capacidad de hacer daño a los demás impunemente; pues quien es capaz de ejecutar acciones injustas y realmente "es un hombre", jamás podrá convenir con nadie "en no cometer ni sufrir iniquidades, pues loco estaría si lo hiciese" ( $359 b)$.

Comentando lo expuesto en $358 a-359 b, \mathbf{R}$. L. Nettleship escribe:

"Esta es la primera aserción escrita que poseemos acerca de una teoría que a partir de entonces ha desempeñado un papel importante en el mundo, a saber, la de que las obligaciones morales tienen su origen (total o parcial-

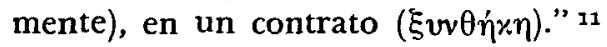

Aun cuando se diga que a los hombres que son "incapaces de elegir entre cometer y sufrir actos injustos" les parece que es útil "convenir" unos con otros en que no incurrirán en tales extremos, el efecto de tal convenio no puede ser, al menos para todos los ciudadanos, una obligación "moral" en el sentido estricto del término, ya que quien es capaz de ejecutar acciones injustas y realmente es "un hombre", jamás podrá convenir con nadie "en no cometer ni sufrir injusticias, pues loco estaría si lo hiciese" (359 b).12

Glaucón no hace en realidad sino repetir una de las tesis que Calicles detiende en el Gorgias, la de que, si bien de acuerdo con la naturaleza lo más infamante es también lo más malo, como padecer injusticias, de acuerdo con la ley, en cambio, lo peor es cometerlas, ya que "ser victima de alguna no es propio de un hombre, sino de un esclavo, para quien ser muerto es preferible a vivir, cuando, sufriendo iniquidades y afrentas, no es capaz de defenderse a sí mismo, ni a otro por quien deba velar". ${ }^{13}$

11 R. L. Nettleship, Lectures on the Republic of Plato, Macmillan, reimpresion del año 1964. "La teoría del contrato -escribe el comentarista inglés- puede ser y ha sido aplicada en apoyo de los intereses más opuestos y en defensa de las posiciones más contradictorias. Como Glaucón la formula, y como debemos aqui tratar con ella, se reduce simplemente a esto: atendiendo a la naturaleza de las cosas lo mejor es cometer injusticias; pero los hombres han descubierto por experiencia que no pueden actuar así impunemente, y el mayor mal es padecer una injusticia cuando no se tiene el poder de desquitarse. Por ello, han buscado la solución del problema en un compromiso, haciendo leyes y fundando instituciones capaces de ponerlos a salvo del mayor mal, pero incapaces de garantizarles el bien más grande" (p. 52).

12 En otros términos: el convenio de no incurrìr en ninguno de los dos extremos: cometer y padecer actos injustos, sólo tiene aplicación, en consonancia con la tesis que Glaucón expone, al caso de los incapaces de optar, es decir, al de los débiles; no al de los poderosos, que invariablemente seguirán -a menos de "estar locos" - el camino de la injusticia.

13 Gorgias, 482-c-483-b. Sobre la doctrina de Calicles: E. García Máynez, Teorias sobre la justicia en los diálogos de Platón, cap. vI. 
Quienes practican la justicia simplemente lo hacen por sentirse impotentes para cometer injusticias, no por respeto a la virtud opuesta. La prueba está -a juicio de Glaucón- en que si diéramos a cada uno, "tanto al justo como al injusto, el poder de hacer lo que les viniere en gana", al primero lo sorprenderíamos en el acto de disponerse a seguir la misma conducta del otro, "a causa de ese propósito de tener más de lo debido que, por naturaleza, todo ser persigue como un bien, aun cuando se vea forzado por la ley al respeto de la igualdad" (359 b).

Por lo tanto, en consonancia con los argumentos de Glaucón:

$1^{\text {g) }}$ Lo que los hombres llaman "justicia" no es realmente una virtud, sino una forma de conducta que sólo se explica porque, quienes la asumen, no tienen el valor de proceder injustamente.

$\left.2^{\circ}\right)$ Por ley natural, todo individuo trata de obtener, en provecho propio y detrimento de sus congéneres, "más de lo debido"; pero esta innata tendencia ( $\pi \lambda \varepsilon o v \varepsilon \xi i$ ia), a menudo es reprimida por poquedad o miedo.

30) Si fuese dado a los humanos el poder de cometer impunemente cualquier delito, no habria hombres justos, sino que todos, sin excepción, preferirían la injusticia a la justicia, y ejercitarían ese poder en la forma en que lo hizo Giges el lidio. Habiendo éste encontrado por azar un anillo de oro con el que podía volverse invisible, se dio a la comisión de toda suerte de crímenes: "logró introducirse en la corte; sedujo a la esposa del monarca y, con ayuda de ésta, se lanzó sobre el rey, le dio muerte y ocupó el trono" $(359 b-360 b)$.

Si por ventura hubiese dos anillos como el de Giges, y el hombre justo se pusiera uno y el injusto el otro, "parecería imposible —sentencia Glaucónencontrar a nadie que, por tener un temple tan duro como el acero, perseverase en la justicia" (360b).

El que urde hábilmente sus iniquidades se oculta siempre al perpetrarlas, si es totalmente injusto, pues al que es sorprendido cuando las comete debemos tenerlo por torpe. "En el supuesto de que el máximamente injusto errare en algo por casualidad, hay que admitir que es capaz de rectificar; que está suficientemente dotado para convencer si alguna de sus injusticias se descubre, y que puede imponerse en forma violenta, usando toda la fuerza necesaria, gracias a su vigor y a su hombría y a los amigos y bienes de fortuna que se ha procurado" ( $361 b)$.

$\mathrm{Si}$ al lado del máximamente injusto colocamos, con el pensamiento, al máximamente justo, "varón sencillo y noble que, como dice Esquilo, no quiere parecer virtuoso, sino serlo en realidad", observaremos que "recibirá honores y recompensas por su reputación", de manera que "no podremos saber si es justo por su justicia o por las recompensas y honores que recibe". Y aun cuando el tal no ejecute ningún acto reprobable, conviene "que tenga la peor reputación de injusticia, a fin de que su espíritu justiciero sea 
puesto a prueba"; que se mantenga "absolutamente inmutable hasta la muerte", pareciendo injusto cuando en el fondo es justo, y que, habiendo llegado tanto él como el inicuo hasta el limite, "uno de la justicia, de la injusticia el otro, pueda juzgarse cuál de ellos es más feliz" (361c-d).

Ocurre, empero, preguntar por qué el justo ha de fingir que es injusto, aun cuando se acepte, como Glaucón lo afirma, que las recompensas que se le tributan nos impedirán saber si es justo por su justicia o por los honores de que se le hace objeto. La duda que el hermano de Platón formula es, pues, del mismo tipo que la que Kant expresa cuando dice que nunca lograremos descubrir, con seguridad completa, si el hombre que ejecuta un acto "conformemente al deber", lo realiza también "por deber", o simplemente "por inclinación".14

Juzgar cuál de los dos hombres, el justo o el inicuo, es más feliz, no será difícil, a juicio de Glaucón, porque, siendo como fueron descritos, el justo se perjudicará a sí mismo con su justicia, en tanto que el otro, el que no quiere parecer, sino ser injusto, "manda en su ciudad por su reputación de justicia; toma esposa de la familia que prefiere; da en matrimonio a sus hijos a quien le viene en gana; trata y se asocia con quienes le place, y de todas estas relaciones saca ventajas y ganancias, porque no tiene empacho en cometer cualquier fechoría. Cuando entra en litigios, privados o públicos, triunfa y se aprovecha de sus contrarios $y$, de este modo, se enriquece; beneficia a sus amigos y daña a sus enemigos; hace sacrificios a los dioses y les dedica otrendas en forma abundante y magnifica, y honra y sirve mejor que el justo a los dioses y a los hombres a quienes quiere bien, de manera que razonablemente puede esperarse que será más grato a las divinidades que el varón justo" $(362 b-c) .{ }^{15}$

I4 Al tratar el problema de la posibilidad de los imperativos categóricos, o imperativos de la moralidad, Kant sostiene que la indole incondicional de éstos dificulta de manera extraordinaria la solución del problema, porque en el caso no hay ningún supuesto de acuerdo con el cual podamos comprobar aquella posibilidad. La experiencia no nos auxiliará en lo más mínimo, ya que no conocemos ejemplo alguno que pruebe que esos impera. tivos existen. Siempre surgirá la sospecha de que los pretendidos imperativos categóricos no son sino meras reglas hipotéticas, ocultas bajo la máscara de un mandamiento incondicionado. Cuando declaramos, verbigracia "no debes prometer falsamente", damos expresión a un imperativo moral; mas no podemos saber si el hombre que cumple sus promesas lo hace exclusivamente por deber u obedece a móviles distintos, como el temor de perder su crédito. En esta última hipótesis, la máxima del sujeto no sería ya la de un imperativo categórico, sino un consejo de la sagacidad, formulable de este modo: "Si quieres conservar tu crédito, cumple indefectiblemente tus promesas."

$15 \mathrm{Si}$-como Sócrates lo sostiene_ la justicia vale en sf y por sí, las eventuales consecuencias de la conducta del justo no pueden alterar, ni menos aún destruir, el valor del comportamiento en cuestión. 


\section{Palabras de Adimanto}

Después de Glaucón, Adimanto interviene para sostener que es necesario recordar los argumentos contrarios, es decir, "los de quienes alaban la justicia y censuran la injusticia" (362e). Éstos aconsejan a sus hijos que sean justos; pero no alaban a la justicia por ella misma, "sino por las consideraciones que engendra", a fin de que "el que parece ser justo logre, por su buena fama, cargos, alianzas y todos los bienes que Glaucón enumeró como los que derivan para el justo de su prestigio" (363a). Los defensores de la $\delta$ เxaıoóvm ponderan aún más, según Adimanto, las ventajas de la nombradía, "y hablan de los abundantes dones que las divinidades conceden a los piadosos, como lo afirma el bueno de Hesíodo y también Homero" (363b). Hablando de los dioses, "Museo y su hijo reservan a los justos bienes aún más espléndidos, pues los llevan al Hades con el pensamiento y, después de preparar el festín de los bienaventurados, los hacen recostarse coronados de guirnaldas, como si el más bello galardón de la virtud fuese una embriaguez eterna" (367c- $d)$.

Las ideas que Adimanto atribuye "a quienes alaban la justicia y censuran la injusticia" parecen oponerse diametralmente a los argumentos aducidos por Glaucón, aunque, bien vistas las cosas, "tienden -como escribe Nettleship - a los mismos resultados prácticos". ${ }^{16}$ Los encomios a que alude el primero, más que de la justicia misma, lo son de los resultados que la fama de ser justo produce en beneficio del que ha sabido adquirirla, aun cuando sólo se trate de una apariencia. Lo que a fin de cuentas importa, si nos atenemos a esas opiniones, no es "ser" virtuoso, sino "pasar por tal". Es cierto que Adimanto no añade, como su hermano, que si el hombre logra ser impunemente injusto, ello será para él el bien más alto. Entre los dos enfoques no hay, empero, gran diferencia, ya que en ambos casos se llega a la conclusión de que lo realmente valioso es la reputación de justicia, no el hecho de ser justo.

Seguidamente, Adimanto trae a colación el parecer de quienes alegan que "Ias acciones injustas son más útiles que las justas", especialmente cuando a la $\alpha \delta \delta x i ́ a$ se hallan unidos el dinero y la influencia, pues "a los malvados que son ricos o poseen otras clases de poder" los demás "los declaran dichosos y no tienen empacho en honrarlos, tanto en público como en privado" (364a).

"Esto, Sócrates, y probablemente aún más - concluye Adimanto- dirían Trasímaco y tal vẹ algún otro acerca de la justicia y la injusticia, invirtiendo torpemente, según creo, la naturaleza de una y de otra. Por mi parte - pues nada te debo ocultar - me he extendido al exponer mi punto de vista tanto cuanto me ha sido posible, porque deseo oirte defender la tesis contraria. 
Pero con tus argumentos no sólo nos muestres que la justicia es superior a la injusticia, sino explícanos por qué, a causa de los efectos que cada una produce en quien la tiene, una es un mal y la otra un bien" $(367 a-b) .{ }^{17}$

\section{La primera polis}

Después de oír las palabras de los hermanos de Platón, Sócrates, en vez de analizar los argumentos expuestos, para refutarlos uno por uno, como lo hizo al discutir con Trasimaco, propone, en forma un tanto brusca, un radical cambio de actitud metódica, pues, a su juicio, el problema sobre la esencia y utilidad de la justicia no es nada fácil, sino que exige una visión muy clara y un planteamiento no sólo distinto, sino mucho más complejo. Ya que nosotros no estamos extraordinariamente dotados - dice a sus interlocutores-, creo que debemos servirnos del mismo método que emplearíamos si "no teniendo suficiente agudeza visual, se nos ordenara leer desde lejos unas letras pequeñas, y después alguien se percatase de que existen también en otra parte, escritas en mayor tamaño y en una superficie más grande, por lo que consideraríamos como una gran suerte haber podido leer primero las mayores y examinar después las otras, para ver si eran las mismas" (368c-d).

No sin sorpresa, Adimanto pregunta a Sócrates qué analogía descubre en ello con la investigación acerca de lo justo.

Si hay una justicia del hombre individual -responde el filósofo- habrá que aceptar también que existe otra de la polis. Pero como la ciudad es mayor que el hombre, más fácil será buscar en la primera la esencia de la

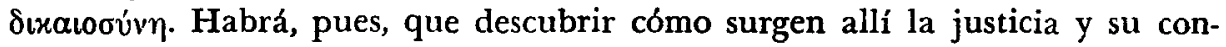
traria. $^{18}$

La ciudad se origina porque el individuo no se basta a sí mismo, sino que ha menester del concurso de sus semejantes. "Recurriendo un hombre a otro en vista de una carencia, y a otro en vista de otra, y faltando a todos muchas cosas, la necesidad los congrega en una misma residencia como asociados y auxiliares." La primera y más urgente de las necesidades humanas es la de alimento; la segunda la de habitaciones y la tercera la de ropa y otros bienes

17 Las palabras finales de la cita parecen indicar que, para Adimanto, la injusticia es un mal y la justicia un bien "por los efectos que cada una produce en quien las práctica".

18 A fin de explicar su método, Sócrates afirma que "sería muy difficil mostrar los efectos de la justicia en la vida interior del individuo, por lo que es mejor principiar no con un análisis del alma, sino con un examen de la naturaleza humana donde puede ser vista 'a mayor escala' . -en 'letras mayores'- como él dice, esto es, en los amplios rasgos del Estado y la sociedad. Principiando con lo externo de aquella naturaleza, donde leer es más fácil, tendremos después que tratar de leer en lo interno, conservando siempre en nuestra mente esas 'letras mayores'. En otras palabras: el método de Sócrates consiste en analizar ciertos hechos relativos a la naturaleza del hombre, notorios para todo el mundo, e inquirir el significado de los mismos hasta llegar eventualmente al más intimo principio de la naturaleza humana, del cual tales hechos son la expresión". Nettleship, op. cit., pp. 67 y 68. 
de igual especie. ¿Cómo podrá nuestra ciudad proveer a todas ellas? El agricultor, que es uno, ¿debe suministrar alimentos a cuatro y gastar cuatro veces más tiempo para producirlos y compartirlos? $O$, "desentendiéndose de aquéllos, ęproducirá para sí sólo una cuarta parte, y empleará las otras tres una en la provisión de una casa, otra en la de un vestido y la última en la de unos zapatos?" (369a-370a). Ello no sería posible, porque ninguno es absolutamente igual a otro, sino que, por naturaleza, todos son distintos y tienen diferentes aptitudes. Si esto es así, se requerirán más de cuatro individuos para formar una polis, pues el agricultor "no hará él mismo su propia azada, ni su arado", y algo semejante ocurrirá en el caso del tejedor o el zapatero.

La naciente polis - prosigue Sócrates_ no sería aún más grande, "aunque le sumáramos boyeros, pastores y otros guardianes de ganado, a fin de que los labriegos tuviesen animales para arar, los constructores bueyes para usarlos con los campesinos en la transportación y los tejedores y los zapateros dispusiesen de cueros y de lana" ( $370 d-e)$.

Será preciso, además, hacer importaciones y contar con hombres para las tareas de intercambio de mercancías, pues la ciudad no debe producir únicamente en su interior las suficientes para el consumo doméstico, sino también las solicitadas por aquellos de quienes espera obtener lo que le hace falta.

Pero - demanda el moralista - ¿dónde podremos encontrar, una vez constituida nuestra pequeña polis, la justicia y la injusticia?

Quizás - responde Adimanto- en la necesidad que sus elementos tienen unos de los otros en sus mutuas relaciones.

Tal vez tengas razón -opina Sócrates. Habrá, pues, que suponer cómo vivirán Ios ciudadanos en Ia comunidad por ellos establecida.

La existencia de los integrantes de la primitiva polis, que más que una ciudad en la acepción sociológica del término ${ }^{19}$ sólo es una aldea, es descrita por Sócrates con estas palabras, que parecen provenir de una novela pastoral y no de una obra de filosofía política: "¿Acaso no producirán trigo, vino, vestidos y calzado, y no construirán casas?... Durante el verano, ¿no trabajarán en su mayoría semidesnudos y sin zapatos, pero en invierno suficientemente abrigados y calzados? Se alimentarán con harina de cebada y trigo que unos cocerán y amasarán otros, para hacer ricas tortas y panecillos que servirán sobre juncos y hojas limpias; y, recostados sobre lechos de hierba cubiertos de nueza y mirto, se banquetearán con sus vástagos, bebiendo su vino coronados de guirnaldas; entonarán himnos a los dioses en gustosa compañia, y no procrearán hijos más allá de sus recursos, a fin de protegerse de la pobreza o de la guerra" (372a-c).

19 Cf. Max Weber, Economia y Sociedad, vol. III, cap. vilr "La ciudad", páginas 217 y siguientes del tomo tercero de la traducción castellana de Eugenio fmaz, Fondo de Cultura Económica, México, 1944. 
La que nos pintas - comenta Glaucón al oír las palabras del filósofomucho se parece a una ciudad de cerdos.

Comprendo lo que quieres decir - responde Sócrates. Pues habrá que explicar no solamente cómo nace una ciudad cualquiera, sino también la que vive en la molicie. La que hemos fundado es una polis sana. Mas si queréis que contemplemos también a la corrompida, no hay ningún impedimento. Sin duda, a algunos no les gustará esa sencilla existencia, sino que querrán tener lechos, mesas y otros muebles, lo mismo que sahumerios, hetairas y golosinas. Será, pues, indispensable agrandar el asentamiento y proveer a todas las necesidades. Los que en vez de conformarse con lo estricto anhelan lo lujoso y lo superfluo, tratarán de que en la ciudad haya poetas, rápsodas, actores, bailarines; necesitarán también maestros, ayas, nodrizas, camareros, barberos, cocineros y porquerizos, así como buen número de médicos, por ser muy distinto del anterior el nuevo género de vida (373d).

El territorio que en un principio podía alimentar a la población, pronto resultará insuficiente. Para agrandarlo, ¿̧habrá que hacer la guerra, sea para cercenar parte del suelo de los vecinos, sea para defender el propio si son ellos los que atacan? Ante la amenaza de tal peligro, la comunidad primitiva sentirá que le falta "una añadidura nada pequeña": la de todo un ejército, que combatirá contra los agresores en defensa de las riquezas comunes.

\section{Cualidades que han de tener los guardianes, y forma en que deben ser educados}

Después de trazar el boceto de la primera polis y exponer de qué manera el despertar de los deseos, impulsos y apetencias de los que no se sacian con la satisfacción de las necesidades elementales conduce al ensanchamiento de la ciudad, a la aparición de nuevas ocupaciones y, en una palabra, al inicio de una etapa de refinamiento, Platón, por boca de Sócrates, explica por qué, al aumentar el número de los habitantes y complicarse su estilo de vida, surge una exigencia que, de no ser atendida, pondria en grave peligro a todos: la de formar un ejército, cuya finalidad consistirá en proteger a la ciudad contra la agresión y ayudarla "a mantener el orden interno", pues - como escribe Nettleship en su comentario a la República- Platón jamás afirma que el objetivo para el cual la polis se constituye "sea la conquista". ${ }^{20}$

A partir de 374a, el filósofo deja de hacer hipótesis sobre el origen de la primera ciudad y el surgimiento de la segunda, y se dedica a exponer con gran detalle cómo la polis corrupta puede, merced a la educación, llegar a convertirse en una organización perfecta. Sobre ésta, como sobre una pantalla que las amplifica, se proyectarán las virtudes de los ciudadanos y permitirán descubrir sin esfuerzo la esencia de la justicia.

20 Nettleship, op. cit., p. 73. 
Siendo la defensa una función social de importancia decisiva, el principio de la especialización de las tareas tendrá que aplicarse a ella en forma mucho más rigurosa. Si la naturaleza "ha dotado especialmente a los individuos para diferentes tipos de trabajo, y para la producción de mercancías se requiere la aptitud natural adecuada, este requisito tendrá que ser mucho más urgente cuando el propósito que se persigue es la salvaguarda del Estado". ${ }^{21}$ Por ello, Sócrates considera que el problema primordial, en lo que atañe a la organización política, es descubrir qué cualidades debe tener un buen guerrero.

Glaucón pregunta a Sócrates si los ciudadanos serán capaces, por sí mismos, de defender a la comunidad.

No _responde el segundo_- porque no es posible que cada uno ejerza bien muchos oficios.

Si hemos prohibido al zapatero que sea, a un tiempo, labrador, tejedor y albañil, por estar convencidos de que sólo hará buenos zapatos si se dedica exclusivamente a tal tarea, del que tiene el propósito de llegar a ser un buen guardián tendremos que exigir que no haga ninguna otra cosa. Y si el de los guardianes es de todos los oficios el más importante, obvio resulta que requerirá mayor destreza y aplicación.

En consonancia con el principio de que cada hombre tiene el deber de elegir la actividad para la que, por naturaleza, esté mejor dotado, en el caso de los guerreros será preciso determinar, ante todo, qué virtudes los convertirán en eficaces defensores de la patria.

Al enfrentarse al problema, Sócrates sostiene que no existe gran diferencia entre el natural de un perro de noble raza y un joven bien nacido.

¿Qué quieres decir con esto? -inquiere Glaucón.

Que tanto el uno como el otro han de poseer vivacidad perceptiva, rapidez para perseguir lo percibido y, además, ser fuertes, por si hubiere necesidad de luchar con la presa $(375 c)$. Es indispensable, sobre todo, que sẹan valientes y que, cuando luchen, en ellos se suscite la cólera.

Mas no sólo ha de esperarse que sean feroces con los enemigos, sino que se muestren apacibles con los amigos, ya que, de lo contrario, no tendrían que esperar de otros su destrucción, sino que ellos mismos la llevarían a cabo (375c). Pero: ¿existirá por ventura una disposición anímica que sea, a un tiempo, apacible y fogosa?... Sócrates sostiene que no es imposible encontrarla, y recuerda a Glaucón lo que ocurre con los perros de noble raza: éstos, por su misma índole, son mansos con las personas con quienes conviven o con las que conocen, pero bravos con las desconocidas. Los guardianes deberán ser como esos canes y, además, tener en su naturaleza amor a la sabiduría.

21 Nettleship, op. cit., p. 74. Hay que tener presente que la palabra "Estado" con que el autor inglés traduce la voz griega polis, no se halla referida al actual concepto genérico, sino al específico de "Estado-ciudad". 
¿Cómo es eso? -interroga Glaucón con extrañeza. No comprendo qué es lo que quieres decir.

Lo que quiero decir - responde Sócrates- puedes observarlo en los perros $y$, a mi juicio, es cosa digna de admiración. Cuando uno de estos animales ve a un desconocido, se enfurece, aun cuando no haya recibido de él ningún mal; en cambio, al que conoce le hace zalamerfas, aunque no haya recibido de él ningún bien. En esta característica se manifiesta una fina "disposición natural", verdaderamente "filosófica" (376a).

¿De qué manera? - demanda Glaucón nuevamente.

Para distinguir entre la presencia amiga y la enemiga, el perro no tiene otro medio que el conocimiento o el desconocimiento del sujeto. Si tal es el único criterio distintivo de que el animal dispone, ¿cómo no va a ser amante de aprender y, en tal sentido, filósofo? Si hemos de continuar con nuestro parangón, habrá que admitir, confiadamente, que también el hombre que debe mostrarse hostil con sus enemigos y afable con sus amigos o, en general, con aquellos a quienes conoce, ha de ser, por naturaleza, amante de la sabiduria.

Así como la excelencia del perro de noble raza encuentra su fundamento en atributos naturales del animal, del mismo modo, las virtudes del buen guerrero se fundan en aptitudes del que más tarde habrá de consagrarse a la carrera de las armas. El llamado a convertirse en un noble y buen guar-

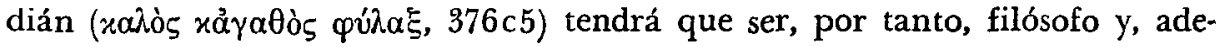
más, colérico, veloz y fuerte. Las mencionadas ảętaí tienen, según lo expuesto, un fundamento ontológico. ${ }^{22}$

Para determinar de qué manera deben ser formados y educados los futuros defensores de la polis habrá que descubrir - a juicio de Sócrates- cómo se originan en ésta la justicia y la injusticia.

Adimanto, tomando la palabra, pregunta al filósofo a qué clase de educación se refiere.

A la que, de acuerdo con una diuturna experiencia, es la mejor que conocemos: la gimnástica para el cuerpo y la música para el alma -responde el hijo de Sofronisco.

¿Con cuál de ellas habrá que empezar? -inquiere Adimanto.

Con la segunda _-contesta Sócrates.

En la música ${ }^{23}$ _inquiere nuevamente Adimanto-_incluyes los discursos?

22 Sobre el fundamento ontológico del concepto de virtud en el pensamiento platónico y aristotélico, consúltese la obra de Hans Joachim Krämer, Arete bei Platon und Aristoteles. Zum Wesen und zur Geschichte der platonischen Ontologie, Carl Winter Universitätsverlag, Heidelbeg, 1959, especialmente, en relación con los libros II-X de la Politica, sección 3 del cap. 1, pp. 83-118.

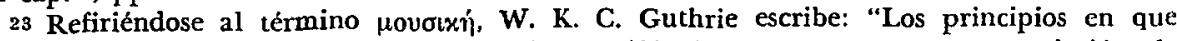

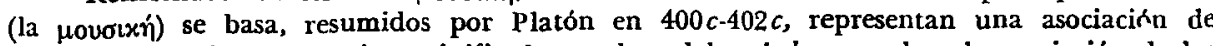
ideas caracteristicamente griega, tipificada por la palabra kalon, a saber, la asociación de los 
Los incluyo; mas no hay que olvidar que, de ellos, unos son verdaderos $\mathrm{y}$ otros falsos.

Como Adimanto declara no entender a qué viene semejante distinción, Sócrates le recuerda que lo primero que se hace con los niños es contarles fábulas, las cuales no son sino mentiras, aun cuando en ellas existe a veces un fondo de verdad. ¿Deberá permitirse que los pequeños escuchen todo tipo de historias o, por el contrario, sólo las que contengan opiniones como las que, a juicio de los pedagogos, aquéllos han de tener cuando alcancen mayor edad? (376e-377b).

Si lo primero no es aconsejable, preciso será vigilar a los que componen esas historias, y aceptar sólo las buenas. Necesario será también persuadir a las nodrizas y a las madres, a fin de que únicamente cuenten a los niños las que hayamos aprobado; en cuanto a las que se narran hoy, tendremos que rechazar la mayor parte.

¿Como cuáles? - pregunta Adimanto.

Como las grandes - responde Sócrates. Y llamo grandes a las que nos han contado Hesiodo, Homero y otros poetas.

¿Qué tienes que censurarles? - demanda el hermano de Glaucón.

Que son mendaces, pues representan a los dioses y a los héroes de modo falso, no como realmente son. Refiriéndose a los entes supremos, Hesíodo, por ejemplo, miente innoblemente sobre los actos que, a juicio suyo, cometió Urano, y sobre la venganza que contra éste tomó Cronos. A ningún adolescente deberá decírsele que nada hay de extraordinario en que las divinidades cometan crímenes o combatan entre sí, si queremos que los futuros guardianes consideren como una gran vergüenza enemistarse con otros. $\mathrm{Y}$ no se diga que aquellos relatos tienen un sentido alegórico, porque los jóvenes no están capacitados para distinguir lo que es alegórico de lo que no lo es.

Como nosotros no somos poetas, sino fundadores de una ciudad -prosigue Sócrates- no nos toca componer las ficciones que pueden conducir a los oyentes a la virtud; pero sí señalar los modelos que los fabulistas han de seguir al componerlas. ${ }^{24}$

En el diálogo sobre la piedad religiosa, Eutifrón, deseoso de justificar la querella presentada por él contra su propio padre, cita, como modelo de su actitud, la conducta de Zeus, alegando que todos los hombres están de acuerdo "en que aquél encadenó a su progenitor por haber, contra toda justicia, devorado a sus hijos". ¿Luego entonces tú crees - le contesta Sócrates- que en realidad "hay guerra de unos dioses contra otros, y odios terribles, y luchas, y tantas otras cosas de igual especie que son referidas por los poetas?" ${ }^{25}$

valores estéticos, sobre todo las cualidades formales de la simetría, la proporción y el ritmo, que a los ojos de los griegos daban unidad a una compleja totalidad de partes, con la excelencia moral." A History of Greek Philosophy, vol. IV, p. 451.

24 Cf. Politeia, $398 c-400 c$.

25 Eutifrón, 6a-6c, 
...Pero retomemos el hilo de nuestro discurso. Cuando Adimanto pregunta qué criterios han de aplicar los fabulistas al escribir sus narraciones, el tilosofo responde:

En primer lugar, tienen el deber de representar siempre a Dios tal cual es, ya sea que lo mencionen en la épica, en la lírica o en la tragedia (379a).

Como Dios es por esencia bueno, y el bien nunca daña, la bondad divina no puede ser causa de todas las cosas, sino exclusivamente de las benéficas. Los que componen las fábulas jamás deberán decir que "Zeus es para nosotros el dispensador de los bienes y los males", ni citar versos como estos de Esquilo: "Dios implanta el crimen entre los mortales, cuando quiere arruinar a una familia" (379e-380a). Les permitiremos, en cambio, sostener que si los malos son desdichados, "es porque necesitan un castigo, y que éste es un beneficio que reciben de la divinidad" ( $380 \mathrm{~b}$ ). Aun cuando las penas sean dolorosas, a la postre se traducen en un bien para quien las sufre, pues, de acuerdo con el fundador de la Academia, "el castigo es la medicina del alma". ${ }^{26}$

Entender el mundo -escribe Nettleship — es descubrir lo que de valioso hay en él. "Ningún hombre logra esto plenamente; pero se trata de un ideal que ha de servir de guía al imperfecto conocimiento humano. Platón asevera que en el Universo, en la medida que el hombre lo experimenta, el mal existe; se trata de un elemento resistente a la acción racional y a la voluntad divinas" (Timeo, 48a y 53b). Mas, con pareja fuerza, también sostiene que "mientras mejor entendemos las cosas, tanto más claramente nos percatamos de que el mal tiene una razón y no es realmente mal". ${ }^{27}$

La primera ley para la educación de los jóvenes deriva de este principio: siendo Dios esencialmente bueno, jamás es causa de los males que padecen los hombres.

A la primera ley habrá que añadir otra, y en ella deberá vedarse a los autores de los mitos que insidiosamente hagan aparecer a la divinidad bajo falsas apariencias, cual si no se tratase de un ente simple, incapaz de abandonar la forma que le es propia (380 d). Que los poetas no digan que "distrazados de huéspedes extranjeros, andan los dioses en todas formas, discurriendo por las ciudades", ni nos presenten a Hera "bajo el disfraz de una sacerdotisa mendicante" $(381 d)$. Y que las madres, bajo el influjo de estas creencias, no amedrenten a sus hijos, contándoles torpemente esos cuen$\operatorname{tos}(381 d)$.

La idea que sirve de base a la segunda norma de que Sócrates habla, es la de la veracidad divina. Ella implica dos cosas, según hemos visto: $1^{a}$ ) que Dios no puede cambiar; $2^{a}$ ) que nunca miente..$^{28}$

26 Gorgias, 478d,

27 Nettleship, op. cit., p. 87.

28 Politeia, $380 \mathrm{~d}$ hasta final del libro II. 
Existen dos especies de cambio: el que viniendo de afuera es producido por un agente externo, y el que tiene su origen en la voluntad del sujeto que decide cambiar.

Los entes que están en su mejor disposición -escribe el filósofo- son los menos susceptibles de que otros los transformen. Los cuerpos más sanos serán los menos afectados por los alimentos, la bebida o el cansancio. En cuanto al alma, la más valiente y sensata es la que en menor grado se ve perturbada por accidentes exteriores. ${ }^{20}$

Los objetos compuestos, por su parte, ya se trate de edificios, muebles o indumentos, si están bien trabajados, resistirán mejor el paso del tiempo y las fuerzas externas (381a).

Sentado el principio de que la naturaleza divina no está sujeta a mudanzas, Sócrates pregunta si los dioses pueden engañarnos, pese a la inmutabilidad de su condición.

La "verdadera mentira" es igualmente aborrecida por los mortales y los inmortales. El verbo $\psi \varepsilon v ́ \delta \varepsilon \sigma \theta \alpha$, además de aplicarse al caso de quien hace un aserto falso con el propósito de engañar a otro, puede también referirse a la persona que se halla en el estado de ignorancia. No hay nada que a nadie repugne más que ser víctima de un engaño respecto de la naturaleza de las cosas y tener que "guardar tal mentira en el alma" (382b).

La verdadera mentira es, pues, la ignorancia que anida en nosotros, porque la otra, la mentira "en las palabras", no es sino una imitación del estado que afecta al alma (382b-c).

La segunda de las dos - inquiere el hijo de Sofronisco- ¿no podrá alguna vez ser útil para alguien y, por tanto, no será ya digna de odio? ¿Mentir no tiene acaso utilidad en los tratos con los enemigos, e incluso respecto de los amigos, cuando por el furor o la demencia éstos pueden intentar la comisión de algún mal?

Pero a Dios, ¿por cuál de estas razones podría la mendacidad resultarle útil? Es indudable que por ninguna. Reconozcamos, en consecuencia, que "lo demoniaco y lo divino se oponen absolutamente a aquélla".

En suma: Dios es algo perfectamente simple y "veraz en los hechos y en las palabras", que ni se muda a sí mismo ni engaña a otros valiéndose de tantasmas o enviándoles signos durante el sueño o la vigilia (382e).

Eduardo García Máynez

Instituto de Investigaciones Filosóficas

Universidad Nacional Autónoma de MÉxico

29 Ibid. $380 \mathrm{c}$. 